\title{
Identification and characterization of Salmonella typhi isolates from Southwest Sumba District, East Nusa Tenggara based on 16S rRNA gene sequences
}

\author{
CHARIS AMARANTINI ${ }^{1, \vartheta}$, LANGKAH SEMBIRING ${ }^{2}$, HARIPURNOMO KUSHADIWIJAYA ${ }^{3}$, \\ WIDYA ASMARA ${ }^{4}$ \\ ${ }^{1}$ Faculty of Biology, Duta Wacana Christian University (UKDW). Jl. Dr. Wahidin Sudirohusodo No. 5-27, Yogyakarta 55224, Indonesia. Tel.: +62-274- \\ 563929. Fax.: +62-0274-4513235. email: charis@ukdw.ac.id \\ ${ }^{2}$ Faculty of Biology, Gadjah Mada University (UGM), Yogyakarta 55284, Indonesia. \\ ${ }^{3}$ Field Epidemiology Training Program, Department of Public Health, Faculty of Medicine, Gadjah Mada University (UGM), Yogyakarta 55284, Indonesia. \\ ${ }^{4}$ Department of Microbiology, Faculty of Veterinary Medicine, Gadjah Mada University (UGM), Yogyakarta 55284, Indonesia.
}

Manuscript received: 9 April 2010. Revision accepted: 23 August 2010.

\begin{abstract}
Amarantini C, Sembiring L, Kushadiwijaya H, Asmara W (2011) Identification and characterization of Salmonella typhi isolates from Southwest Sumba District, East Nusa Tenggara based on 16S rRNA gene sequences. Biodiversitas 12: 1-6. The incidence rate of typhoid fever in the Southwest Sumba District, East Nusa Tenggara was approximately about 725/100,000. In spite of such rate, there was not much known-yet about the molecular epidemiology of the disease. Thus, having accurate data and a strong discriminatory ability was crucial to scrutinize the molecular epidemiology of $S$. typhi with a molecular phylogenetic approach based on 16S rRNA gene sequences. Sixteen isolates representative of $S$. typhi from different geographical regions in Southwest Sumba District along with the reference strain $S$. typhi NCTC 786 had been identified and characterized based on 16S rRNA gene sequences using PCR amplification and sequencing. The $16 \mathrm{~S}$ rRNA sequences data were aligned with the corresponding available $S$. typhi sequences retrieved from the NCBI database by using CLUSTAL X software. Phylogenetic trees were generated with PHYLIP software package. Molecular phylogenetic analysis indicated that all the isolates belong to $S$. typhi species were suggested by their relativity with the type strain of $S$. typhi ATCC $19430^{\mathrm{T}}$. It was also found that the isolates which belong to $S$. typhi species formed several different centers of diversity within the 16S rRNA gene tree. Each clade consisted of the strains from different geographical places in the District. Thus, to conclude the inquiry, there was evident inter-geographical spread of the strains and it tended to spread further into more remote areas in the District.
\end{abstract}

Key words: Salmonella typhi strains, typhoid fever, 16S rRNA gene sequences, molecular phylogenetic analysis.

\section{INTRODUCTION}

There are 17 to 22 million cases of typhoid fever worldwide per year and it causes 216,000 to 600,000 deaths annually (Steele 2008). Based on a preliminary survey, the fever was highly endemic in Southwest Sumba District, East Nusa Tenggara and it infected 725/ 100,000 people per year in the District according to the report made by Karitas Hospital in 2006. Until recently however it has not been under controlled because the limitations of health service units to diagnose the typhoid through laboratory studies. The incidence rate in the area was higher than the incidence in rural areas $(358 / 100,000)$ or semi rural areas (157/100,000 inhabitants). It was nearly the same as the total number of people infected in urban areas $(810 / 100,000)$ annually in Indonesia (WHO 2003).

Typhoid fever is an acute systemic infection caused by Salmonella enterica subsp. enterica serotype typhi (Salmonella typhi). The acute systemic infection causes $S$. typhi get into the blood stream after passing through several organs in the host. This disease shows clinical symptoms ranging from mild illness with slight fever, the body feels uncomfortable, coughing and the clinical circumstances such as severe abdominal pain and complications. This condition could often cause difficulties to diagnose it when merely based only on clinical symptom (Muliawan and Surjawidjaja 1999). In addition to such high rate, information about the molecular epidemiology of the disease was unknown. Thus, it was indispensable to have accurate data and a strong discriminative ability to distinguish the types of the strains of the pathogenic bacteria needed in the epidemiological study.

The application of the molecular detection methods for the epidemiological study was advantageous because the genetic profile of the bacteria is a source of information to map the spread of the bacteria in the community. Henceforth it is beneficial to determine best-fitted control strategies over the disease. With the given rationale, this study was aimed to unravel the strain diversities belonging to the $S$. typhi species isolated from typhoid fever patients using a molecular phylogenetic approach based on $16 \mathrm{~S}$ rRNA gene sequences, and also to understand the spread of $S$. typhi based on its varieties and interrelations among the 
strains isolated from the infected patients in Southwest Sumba District, East Nusa Tenggara.

\section{MATERIALS AND METHODS}

\section{Bacterial strains}

In this inquiry, there were 16 representative isolates of $S$. typhi from different geographical regions in Southwest Sumba District. They were from infected patients in Karitas Hospital in Weetabula, a private clinic in Elopada Subdistrict in Southwest Sumba District, and Lende Moripa Hospital in Waikabubak, West Sumba District. Specimen collection and microbiological identification methods were described in the journal article published previously (Amarantini et al. 2009).

\section{Extraction of bacterial DNA, PCR amplification and DNA sequencing}

Bacterial DNA was extracted in accordance with the protocol's instructions using a Purelink ${ }^{\mathrm{TM}}$ Genomic DNA Mini Kit (Invitrogen K1820-00). The bacterial DNA and control were amplified with $0.2 \mu \mathrm{M}$ primers (Invitrogen ${ }^{\mathrm{TM}}$ ) and PCR SuperMix (Invitrogen ${ }^{\mathrm{TM}}$ 11306-016). PCR amplification for the 16S rRNA sequences showed bands of $428 \mathrm{bp}, 484 \mathrm{bp}$, and $483 \mathrm{bp}$. These fragments were amplified using primer SR1/SR2, SR3/SR4, and SR5/SR6 respectively. The primers which were used to amplify these fragments showed at Table 1 (Massi et al. 2005). The PCR mixtures were amplified for 40 cycles at $94^{\circ} \mathrm{C}$ for 1 minute, $55^{\circ} \mathrm{C}$ for 1 minute, and $72^{\circ} \mathrm{C}$ for 2 minutes, with a final extension at $72^{\circ} \mathrm{C}$ for 10 minutes in automated Applied Biosystems GeneAmp PCR System 2400. An aliquot of 10 $\mu \mathrm{L}$ of each amplified product was electrophorezed in $1.5 \%$ (wt/vol) agarose gel, with a DNA Molecular Weight Marker (Gel Pilot 100bp Ladder 100 Lanes, Qiagen, Germany) in parallel.

The PCR product was gel purified with a QIAquick PCR purification kit (QIAgen, Germany). The purified PCR product was sequenced with ABI Prism 3100-Avant Genetic Analyzer in accordance with the manufacture's instructions (Applied Biosystems, USA) using PCR primers (Massi et al. 2005).

Analysis and alignment of 16S rRNA nucleotide sequences The 16S rRNA nucleotide sequences were analyzed,

Table 1. The primers used for PCR amplification of 16S rRNA gene sequence of $S$. typhi (Massi et al. 2005).

\begin{tabular}{|c|c|c|c|}
\hline Primer & & Sequence & Nucleotide position \\
\hline SR1 & $5^{\prime}$ & AGTTTGATCCTGGCTCAG $3^{\prime}$ & 3-20 (AC: Z47544) \\
\hline SR2 & $5^{\prime}$ & AGTACTTTACAACCCGAAGG $3^{\prime}$ & 411-430 (AC: Z47544) \\
\hline SR3 & $5^{\prime}$ & AAGTACTTTCAGCGGGGA $3^{\prime}$ & 424-441 (AC: Z47544) \\
\hline SR4 & $5^{\prime}$ & TTGAGTTTTAACCTTGCGG $3^{\prime}$ & 898-916 (AC: Z47544) \\
\hline SR5 & $5^{\prime}$ & ААСТСАAATGAATTGACGG $3^{\prime}$ & 901-919 (AC: Z47544) \\
\hline SR6 & $5^{\prime}$ & AGGCCCGGGAACGTATTCAC 3' & 1364-1383 (AC: Z47544) \\
\hline
\end{tabular}

Note: AC: GenBank accession no. edited and assembled with Finch TV 1.4.0 and DNA Baser sequence analysis software. Complete assembled sequences were aligned with the corresponding $S$. typhi sequences retrieved from the NCBI database with CUSTAL X software (Thompson et al. 1997).

\section{Construction of phylogenetic tree}

Based on 16S rRNA nucleotide sequences, a phylogenetic tree was constructed with PHYLIP software package (Felsenstein 1993) with the neighbor-joining algorithm (Saito and Nei 1987). The evolutionary distance matrix for the neighbor-joining method was generated in accordance with the description introduced by Jukes and Cantor (1969). The phylogenetic distances were obtained by adding only the values of the horizontal components. Eventually, the matrix of the nucleotide similarity and difference was generated with PHYDIT software (Chun 1999).

\section{Mapping the spread of S. typhi strains in Southwest Sumba District, East Nusa Tenggara}

The spread of $S$. typhi strains was isolated from the endemic regions in Southwest Sumba District was mapped according to the infected patients' residences using a satellite navigation system (Global Positioning System /GPS). The spread of the strain types and the phylogenetic relationships among the strains, as the results of the $16 \mathrm{~S}$ rRNA gene sequencing, were also mapped according to the geographical distribution of the diseases.

\section{RESULTS AND DISCUSSION}

Molecular characterization of $S$. typhi strains using
phylogenetic approach based on 16S rRNA gene sequences
Based on 16S rRNA gene, the phylogenetic analysis of the 16 isolates of $S$. typhi from different geographical origins in Southwest Sumba District is shown in Figure 1. There were 29 isolates of 16S rRNA gene sequences used in constructing the phylogeny tree. It consisted of $18 \mathrm{~S}$. typhi strains, including the type strain of $S$. typhi ATCC $19430^{\mathrm{T}}$ (accession no. Z47544) which belonged to $S$. enterica, one strain belonged to $S$. bongori BR 1859 (AF029227), and 11 strains from Enterobacteriaceae family [Escherichia coli ATCC 25922 (X80724.1), Citrobacter freundii ATCC 29935 (M59291.1), Serratia marcescens (M59160.1), Erwinia carotovora ATCC 15713 (M59149.1), Yersinia ruckeri ATCC 29473 (X75275.1), Yersinia intermedia ER-3854 (X75279.1), Hafnia alvei ATCC 13337 (M59155.1), Photobacter luminescens DSM 3368 (X82248.1), Xenorhabdus nematophilus DSM 3370 (X82251.1), Proteus vulgaris IFAM 1731 (X07652.1), and Plesiomonas shigelloides (M59159)]. Plesiomonas shigelloides was used as the out group strain in the root position since this species belongs to 
Enterobacteriaceae family and it formed a separate sub-line of descent of the evolution of Salmonella, E. coli, and $C$. freundii (Chang et al. 1997).

The result of the phylogenetic analysis (Figure 1) showed that 16 representative isolates of $S$. typhi from various regions in Southwest Sumba District, East Nusa Tenggara belonged to $S$. typhi species because of their relativity with the type strain of $S$. typhi ATCC $19430^{\mathrm{T}}$. They formed several different centers of diversity within the $16 \mathrm{~S}$ rRNA gene tree. All the strains fell into four clades and form a clear center of diversity with the reference strain of S. typhi ATCC $19430^{\mathrm{T}}$.

The first clade consisted of eight strains, namely BPE 121.1-MC isolates from Weedindi in East Wewewa Subdistrict, RSK 32.1-CCA isolates from Pakamutu in Kodi Subdistrict, two isolates (BPE 122.1-CCA and BPE 122.4-CCA) from Durru Lodo in East Wewewa Subdistrict, other two isolates (BPE 127.1-MC and BPE 127.2-MC) from Elopada in East Wewewa Subdistrict, BPE 123.1-CCA isolates from Kongge in East Wewewa, and one isolates (BPE 120.1-MC) from Omba Rade in East Wewewa Subdistrict.

According to the previous research (Amarantini et al. 2009), two isolates (BPE 121.1-MC and BPE 127.1-MC) were categorized as Biotype III (d-xilose +; 1-arabinose +). All the others (RSK 32.1-CCA, BPE 122.1-CCA, BPE 122.4-CCA, BPE 127.2-MC, BPE 123.1-CCA and BPE 120.1-MC) were categorized as Biotype I (d-xilose +; 1arabinose -). Both categories were classified as one single clade. In the first clade, it was evident that the resistant strains and the sensitive strains from the same geographical area could be separated into different subclades. The strains were BPE 127.1-MC and BPE 127.2-MC from Elopada in East Wewewa and BPE 122.1-CCA and BPE 122.4-CCA from Durru Lodo in East Wewewa. This research proved that the phylogenetic classification for the first clade could differentiate two strains with different characters in terms of their nalidixic acid resistance in separate subclade even though they were originally from the same geographical origin.

The second clade consisted of four strains, they were BPE74.1-CCA isolates from Weerambo, East Wewewa, RSL 1.3-SSA isolates from Kampung Sawah, Waikabubak, BPE 7.10-MC isolates from Ombawawi, North Wewewa, BPE 1.1-SSA isolates from Wanowitu, East Wewewa. It meant that four isolates in this clade were closely related with $S$. typhi NCTC 786 . According to the database, this strain was a culture collection of HPA in United Kingdom deposited by the Lister Institute (accession data: 01.01.1920). It was isolated in 1920 from a single colony of S. typhi Rawlings strains, NCTC 160. According to WHO standard, this strain was categorized in the third group as hazardous pathogens. Thus, people should be very cautious to these strains.

The third clade consisted of three strains; they are RSK 5.1-SSA isolates from Watubero in North Kodi Subdistrict and two isolates (RSK 22.2-CCA and RSK 22.4-CCA) from Pala Mata Loko in North Wewewa. In this clade, the strains belong to Biotype I and Biotype III. All these isolates were sensitive to nalidixic acid.
The last clade was named Clade Palekki since it comprised of the isolates originally from Palekki in North Wewewa Subdistrict. It belonged to Biotype I. This clade was the most different isolates among the sixteen isolates because it was a single-member clade which contained only one isolate (BPE 88.1-CCA).

The 16S rRNA nucleotide similarity values $(\%)$ and the number of nucleotide differences among $16 \mathrm{~S}$. typhi isolates from the infected patients in different geographical regions in Southwest Sumba District and the reference strain of $S$. typhi ATCC $19430^{\mathrm{T}}$ are shown in Table 2. All the tested strains possess a 16S rRNA sequence with $\searrow 99 \%$ similarity with the reference strain of $S$. typhi ATCC $19430^{\mathrm{T}}$. Based on the similarity scores, these strains were identified as S. typhi (Drancourt et al. 2000). They were entirely congruent either between similarity values and nucleotide differences or based on the phylogenetic analysis. Thus, this inquiry concluded that the isolates belong to $S$. typhi species even though they formed several different centers of diversity within the $16 \mathrm{~S}$ rRNA gene tree.

It was also evident that in terms of similarity and difference of nucleotide (Table 2), BPE 122.4-CCA was identical with BPE 122.1-CCA. BPE 122.1-CCA was also like BPE 121.1-MC and BPE 120.1-MC. The last two strains (BPE 121.1-MC and BPE 120.1-MC) were identical. All these strains were originally from East Wewewa Subdistrict and classified into the first clade. Consequently, the similarity values and the number of nucleotide differences between the strains were completely congruent with the results of the phylogenetic analysis.

\section{Analysis of S. typhi isolates according to geographical distribution of the diseases using global positioning system and its public health implications}

The map of the $S$. typhi isolates according to the geographical distribution of the diseases using Global Positioning System is shown in Figure 2. It revealed that the phylogenetic relationships of $S$. typhi strains were based on the phylogenetic distance value. In addition, the result of phylogeny tree analysis also shows that each clade was made up of the strains from different places of origin in Southwest Sumba District, East Nusa Tenggara. This fact indirectly answers the hypothesis of inter-geographical spread of the strains.

The spread of the strains within the first clade originated from Durru Lodo, East Wewewa. It reached out Weedindi in East Wewewa Subdistrict and went further out to Pakumutu in Kodi Subdistrict. The transmission was indicated with the brown line. The other three strains of the same clade spread circulatory in the territory of East Wewewa Subdistrict. As indicated by the red line, the strain from Ombarade spread outward to Elopada and Kongge (Figure 2).

In the second clade, the strain from Wanowitu in East Wewewa Subdistrict spread outward to Ombawawi in North Wewewa Subdistrict, and then went further out to Kampung Sawah in Waikabubak Subdistrict and Weerambo in East Wewewa Subdistrict. The spread of these strains is indicated with the purple line (Figure 2). 


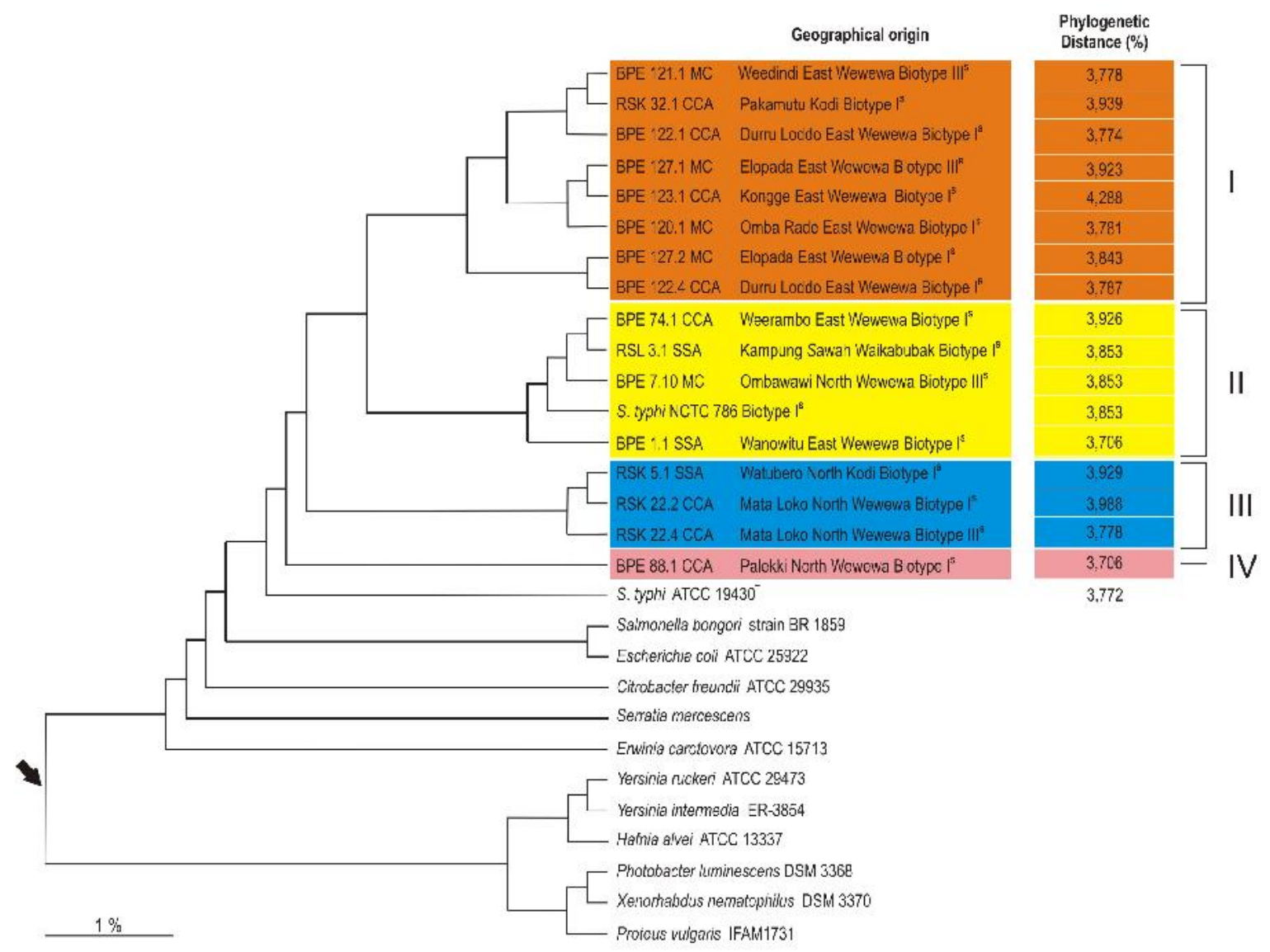

Figure 1. Neighbor-joining (Saitou and Nei 1987) dendogram represents the phylogenetic relationships of the 16S rRNA gene of $S$. typhi strains from different geographical areas in Southwest Sumba District, East Nusa Tenggara and the representative strains of Enterobacteriaceae family. The arrow indicates estimated root.
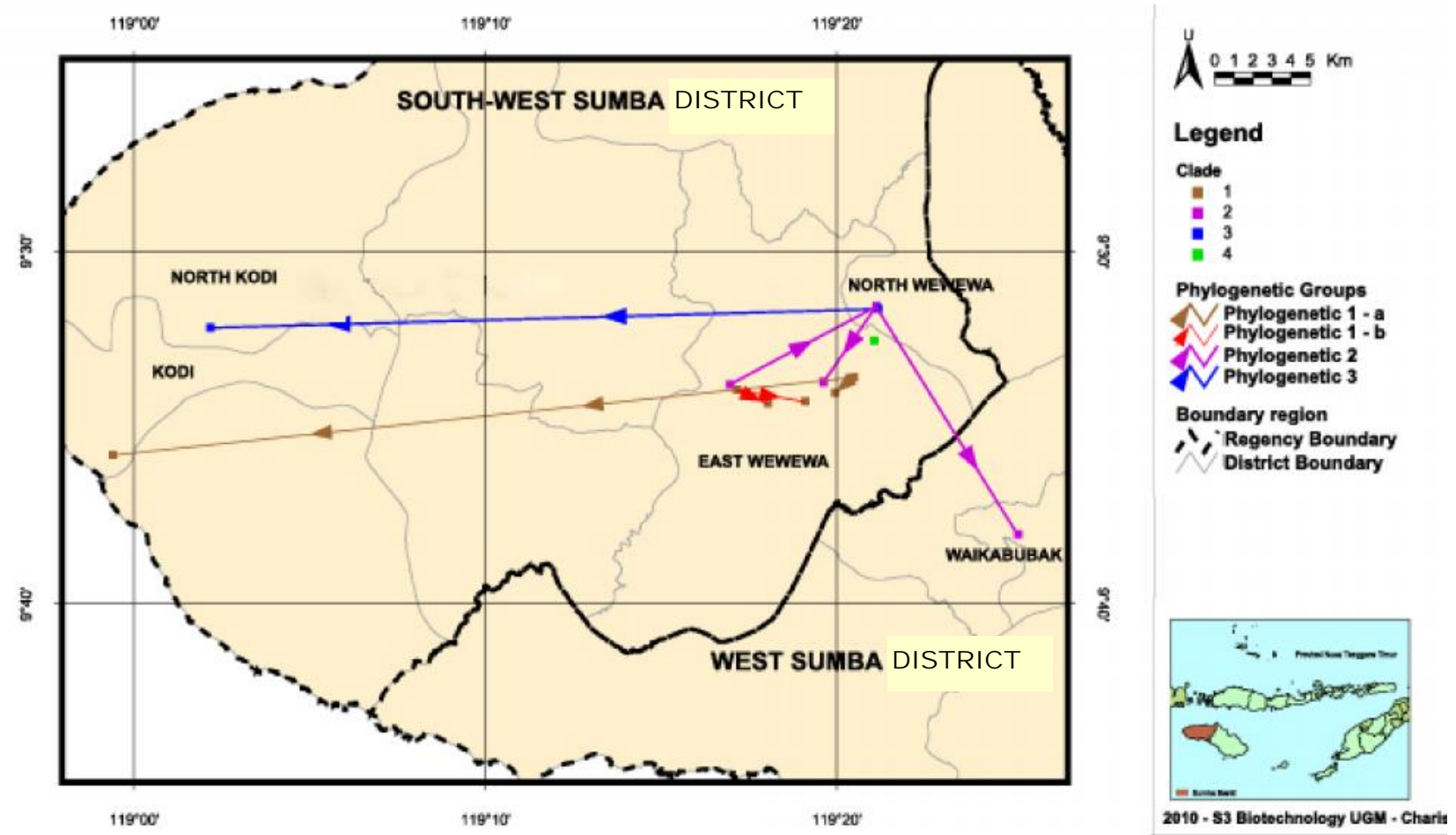

Figure 2. The map of diversity and distribution of S. typhi strains in Southwest Sumba District, East Nusa Tenggara based on phylogenetic relationships. 
Table 2. 16S rRNA similarities value (\%) and the number of nucleotide difference between the sixteen strains of $S$. typhi originated from different geographical places in Southwest Sumba District, East Nusa Tenggara and the reference strain of S. typhi ATCC $19430^{\mathrm{T}}$.

\begin{tabular}{|c|c|c|c|c|c|c|c|c|c|c|c|c|c|c|c|c|c|c|}
\hline $\begin{array}{c}\text { Strain } \\
\text { code }\end{array}$ & $\mathbf{A}$ & $\mathbf{P}$ & $\mathbf{E}$ & $\mathbf{R}$ & $\mathbf{K}$ & $\mathbf{O}$ & $\mathbf{J}$ & B & $\mathbf{L}$ & $\mathbf{M}$ & D & $\mathbf{N}$ & $\mathbf{F}$ & $\mathbf{H}$ & I & $\mathbf{Q}$ & $\mathbf{G}$ & Z47544 \\
\hline A & --- & $5 / 1384$ & $4 / 1382$ & $5 / 1381$ & $4 / 1382$ & $6 / 1382$ & $4 / 1382$ & $6 / 1382$ & $4 / 1381$ & $4 / 1382$ & $5 / 1380$ & $11 / 1381$ & $5 / 1381$ & $3 / 1381$ & $6 / 1381$ & $5 / 1381$ & $4 / 1381$ & 7/1381 \\
\hline $\mathrm{P}$ & 99.64 & --- & $3 / 1382$ & $4 / 1381$ & $1 / 1382$ & $3 / 1382$ & $1 / 1382$ & $3 / 1382$ & $1 / 1381$ & $1 / 1382$ & $6 / 1380$ & $8 / 1381$ & $4 / 1381$ & $2 / 1381$ & $5 / 1381$ & $4 / 1381$ & $3 / 1381$ & $6 / 1381$ \\
\hline $\mathrm{E}$ & 99.71 & 99.78 & --- & $3 / 1381$ & $2 / 1382$ & $4 / 1382$ & $2 / 1382$ & $4 / 1382$ & $2 / 1381$ & $2 / 1382$ & $4 / 1380$ & $9 / 1381$ & $3 / 1381$ & $1 / 1381$ & $4 / 1381$ & $3 / 1381$ & $2 / 1381$ & $5 / 1381$ \\
\hline $\mathrm{R}$ & 99.64 & 99.71 & 99.78 & --- & $3 / 1381$ & $5 / 1381$ & $3 / 1381$ & $5 / 1381$ & $3 / 1381$ & $3 / 1381$ & $6 / 1380$ & $10 / 1381$ & $4 / 1381$ & $2 / 1381$ & $5 / 1381$ & $4 / 1381$ & $3 / 1381$ & $6 / 1381$ \\
\hline K & 99.71 & 99.93 & 99.86 & 99.78 & --- & $2 / 1383$ & 0/1383 & $2 / 1382$ & 0/1381 & $1 / 1383$ & $5 / 1380$ & $7 / 1381$ & $3 / 1381$ & $1 / 1381$ & $4 / 1381$ & $3 / 1381$ & $2 / 1381$ & $5 / 1381$ \\
\hline $\mathrm{O}$ & 99.57 & 99.78 & 99.71 & 99.64 & 99.86 & --- & $2 / 1383$ & $4 / 1382$ & $2 / 1381$ & $3 / 1383$ & $7 / 1380$ & $8 / 1381$ & $5 / 1381$ & $3 / 1381$ & $6 / 1381$ & $5 / 1381$ & $4 / 1381$ & $7 / 1381$ \\
\hline J & 99.71 & 99.93 & 99.86 & 99.78 & 100 & 99.86 & --- & $3 / 1383$ & 0/1381 & $1 / 1384$ & $5 / 1381$ & $7 / 1382$ & $3 / 1382$ & $1 / 1381$ & $4 / 1381$ & $3 / 1381$ & $2 / 1381$ & $5 / 1381$ \\
\hline B & 99.57 & 99.78 & 99.71 & 99.64 & 99.86 & 99.71 & 99.78 & --- & $2 / 1381$ & $3 / 1383$ & 7/1381 & $10 / 1382$ & $6 / 1382$ & $3 / 1381$ & $6 / 1381$ & $5 / 1381$ & $4 / 1381$ & $7 / 1381$ \\
\hline $\mathrm{L}$ & 99.71 & 99.93 & 99.86 & 99.78 & 100 & 99.86 & 100 & 99.86 & --- & 0/1381 & $5 / 1380$ & $7 / 1381$ & $3 / 1381$ & $1 / 1381$ & $4 / 1381$ & $3 / 1381$ & $2 / 1381$ & $5 / 1381$ \\
\hline M & 99.71 & 99.93 & 99.86 & 99.78 & 99.93 & 99.78 & 99.93 & 99.78 & 100 & --- & $5 / 1381$ & $7 / 1382$ & $3 / 1382$ & $1 / 1381$ & $4 / 1381$ & $3 / 1381$ & $2 / 1381$ & $5 / 1381$ \\
\hline $\mathrm{D}$ & 99.64 & 99.57 & 99.71 & 99.57 & 99.64 & 99.49 & 99.64 & 99.49 & 99.64 & 99.64 & --- & $10 / 1381$ & $6 / 1381$ & $4 / 1380$ & $7 / 1380$ & $6 / 1380$ & $5 / 1380$ & $8 / 1380$ \\
\hline $\mathrm{N}$ & 99.2 & 99.42 & 99.35 & 99.28 & 99.49 & 99.42 & 99.49 & 99.28 & 99.49 & 99.49 & 99.28 & --- & $10 / 1382$ & $8 / 1381$ & $12 / 1382$ & $11 / 1382$ & $9 / 1381$ & $12 / 1381$ \\
\hline $\mathrm{F}$ & 99.64 & 99.71 & 99.78 & 99.71 & 99.78 & 99.64 & 99.78 & 99.57 & 99.78 & 99.78 & 99.57 & 99.28 & --- & $2 / 1381$ & $5 / 1381$ & $4 / 1381$ & $3 / 1381$ & $6 / 1381$ \\
\hline $\mathrm{H}$ & 99.78 & 99.86 & 99.93 & 99.86 & 99.93 & 99.78 & 99.93 & 99.78 & 99.93 & 99.93 & 99.71 & 99.42 & 99.86 & --- & $3 / 1381$ & $2 / 1381$ & $1 / 1381$ & $4 / 1381$ \\
\hline I & 99.57 & 99.64 & 99.71 & 99.64 & 99.71 & 99.57 & 99.71 & 99.57 & 99.71 & 99.71 & 99.49 & 99.13 & 99.64 & 99.78 & --- & $1 / 1382$ & $4 / 1381$ & $7 / 1381$ \\
\hline Q & 99.64 & 99.71 & 99.78 & 99.71 & 99.78 & 99.64 & 99.78 & 99.64 & 99.78 & 99.78 & 99.57 & 99.2 & 99.71 & 99.86 & 99.93 & --- & $3 / 1381$ & $6 / 1381$ \\
\hline G & 99.71 & 99.78 & 99.86 & 99.78 & 99.86 & 99.71 & 99.86 & 99.71 & 99.86 & 99.86 & 99.64 & 99.35 & 99.78 & 99.93 & 99.71 & 99.78 & --- & $3 / 1381$ \\
\hline Z47544 & 99.49 & 99.57 & 99.64 & 99.57 & 99.64 & 99.49 & 99.64 & 99.49 & 99.64 & 99.64 & 99.42 & 99.13 & 99.57 & 99.71 & 99.49 & 99.57 & 99.78 & --- \\
\hline
\end{tabular}


In the second clade, the strain from Wanowitu in East Wewewa Subdistrict spread outward to Ombawawi in North Wewewa Subdistrict, and then went further out to Kampung Sawah in Waikabubak Subdistrict and Weerambo in East Wewewa Subdistrict. The spread of these strains is indicated with the purple line (Figure 2).

In the third clade, the strain from Mataloko in North Wewewa Subdistrict spread outward to Watubero in North Kodi Subdistrict (blue line). There was one strain (RSK 22.4-CCA) from North Wewewa Mataloko, which was originally able to use 1-arabinose (biotype III). Later on it shifted into a strain of RSK 22.2-CCA which has no ability to use carbon sources (biotype I). The phylogenetic distance showed that the horizontal line of the strain was longer than that of the strains capable of using arabinose as the source of carbon. This fact proved that the strain of $S$. typhi Biotype I strains came up after the strain of $S$. typhi biotype III.

Based on the distribution of $S$. typhi strains in Southwest Sumba District NTT, it was evident to conclude that the diversity and the spread of the strains were high only in East Wewewa Subdistrict. From the region, it spread outward to nearby subdistricts such as North Wewewa and Waikabubak, and then went further out to Kodi and North Kodi. The phylogenetic relationships of $S$. typhi strains based on the phylogenetic distance value significantly showed that the spread of the diseases as indicated with the blue line and the brown line tends to widen to more remote areas.

This tendency should get attention because the strains which were originally from East Wewewa were very diverse, some of which were known to be resistant to nalidixic acid. Moreover, the people who lived in the remote rural areas have difficult lives, not only poor in economy but also poor in sanitation, food, water, commodities, and limited medical care. Thus, it was necessary to prevent the spread of the disease from East Wewewa Subdistrict and to cut off all related factors supporting its transmission.

\section{CONCLUSION}

All S. typhi isolates from the infected patients in Karitas Hospital in Southwest Sumba District, East Nusa Tenggara belonged to $S$. typhi species because of their relativity with the type strain of $S$. typhi ATCC $19430^{\mathrm{T}}$. The genetic diversity of the strains within $S$. typhi species could be disclosed using a molecular genetic approach based on $16 \mathrm{~S}$ rRNA gene sequences. It was evident that the isolates belonging to $S$. typhi species form several different centers of diversity within the $16 \mathrm{~S}$ rRNA gene tree. Each clade consisted of the strains from different places of origin in
Southwest Sumba District, East Nusa Tenggara. Therefore, it was reasonable to conclude that there was intergeographical spread of the strains and it tended to spread outward to more remote areas.

\section{ACKNOWLEDGEMENTS}

A special gratitude is given to Karitas Hospital in Weetabula in Southwest Sumba District and Lende Moripa Hospital in Waikabubak in West Sumba District, East Nusa Tenggara for their assistance in collecting the samples. I should also thank Sr. Sili Bouka ADM-the Director of Karitas Hospital, dr. Loeta Lapoe Moekoe-the Director of Lende Moripa Hospital and all doctors of Karitas Hospital for their assistance during the research.

\section{REFERENCES}

Amarantini C, Sembiring L, Kushadiwijaya H, Asmara W (2009) Isolation, characterization and grouping of Salmonella typhi strains in the Southwest Sumba Regensy East Nusa Tenggara based on phenotypic characteristics. J Biol Res 14: 191-196.

Chang HR, Loo LH, Jeyaseelan K, Earnest L, Stackebrandt, E (1997) Phylogenetics relationships of Salmonella typhi and Salmonella typhimurium based on 16S rRNA sequence analysis. Int J Syst Bacteriol 47: 1253-1254.

Chun J (1999) Phylogenetic Editor (PHYDIT). Windows Version.

Drancourt M, Bollet C, Carlioz A, Martelin R, Gayral JP, Raoult D (2000) $16 \mathrm{~S}$ ribosomal DNA sequence analysis of a large collection of environmental and clinical unidentifiable bacterial isolates. J Clin Microbiol 38: 3623-3630.

Felsenstein J (1993) Phylogeny Inference Package version 3,5c. Distributed by the author. Departement of Genetics, University of Washington. Seattle USA.

Juke TH, Cantor CR (1969) Evolution of protein molecules. In: Munro HN (eds) Mammalian protein metabolism. Academic Press, New York.

Massi MN, Shirakawa T, Gotoh A, Hatta M, Kawabata M (2005) Identification and sequencing of Salmonella enterica Serotype Typhi isolates obtained from patients with perforation and non-perforation typhoid fever. Southeast Asian J Trop Med Public Health. 36: 118122.

Muliawan SY, Surjawidjaja JE (1999) Early diagnosis of typhoid fever by using outer membrane protein of $S$. typhi as specific antigen. Cermin Dunia Kedokteran. 124: 11-13. [Indonesia]

Saitou N, Nei M (1987) The Neighbor-joining method: a new method for reconstructing phylogenetic trees. Mol Biol Evol 4: 406-425.

Steele D (2008) The importance of generating evidence on typhoid fever for implementing vaccination strategies. $J$ Infect Developing Countries 2: 250-252.

Thompson JD, Gibson TJ, Plewniak F, Jeanmougin F, Higgins DG (1997) The CLUSTAL_X windows interface: flexible strategies for multiple sequence alignment aided by quality analysis tools. Nucleic Acids Res 25: 4876-4882.

WHO (2003) Background document: the diagnosis, treatment and prevention of typhoid fever. Communicable Disease Surveillance and Response Vaccines and Biologicals. whqlibdoc.who.int/hq/2003/ WHO_V\&B_03.07.pdf. 